\title{
CINTE YIN GALEMA
}

\author{
Oleh : Renny Destiani \\ (Pembimbing Tugas Akhir : Drs.Yohanes Subowo, M.Sn dan Dra. Tutik Winarti, M.Hum) \\ Jurusan Tari, Fakultas Seni Pertunjukan Institut Seni Indonesia Yogyakarta \\ Alamat Email: rennydestiani2@gmail.com
}

\begin{abstract}
RINGKASAN
Karya tari yang berjudul Cinte Yin Galema diambil dari nama seorang tokoh yang sangat berpengaruh di kerajaan Balok pulau Belitung dan merupakan seorang putri keturunan Tiongkok berparas cantik dan berjiwa kesatria. Yin Galema menceritakan sosok putri Cina yang akrab dengan kebudayaan Melayu seperti cara berpakaian dan bersikap sopan santun di dalam kerajaan Melayu Belitung. Seorang putri ini memilik hasrat dan keinginan yang luar biasa untuk menjaga janji suci pernikahannya dengan suami yang bukan berasal dari golongan manusia, suami yang dimiliki oleh Yin Galema merupakan makhluk bunian yang berarti makhluk keturunan bangsa jin yang memiliki kekuasaan di Pulau Belitung. Karya ini memunculkan sosok laki-laki bunian, dalam hal ini penata menyimbolkan sesuatu yang berbeda alam dengan memunculkan sosok bunian di bagian belakang panggung seperti hanya bayangan sesosok laki-laki yang tidak terlihat.
\end{abstract}

Kehidupan cinta Yin Galema yang sangat indah walaupun berbeda alam namun bisa saling menyentuh berkat pertolongan Raja pertama kerajaan Balok, dengan kekuatan supranatural yang digunakannya dalam bentuk sebuah gelang sakti dan dapat membuat Yin Galema masuk ke dalam dunia makhluk bunian, kehidupan cinta Yin Galema dibangun dengan sangat sempurna, tanpa ada satu orangpun yang mengetahuinya kecuali Raja pertama kerajaan Balok. Yin Galema yang dikenal dengan paras cantiknya membuat semua lelaki yang ada di kerajaan Balok jatuh cinta dan tergilagila dengan wajah indahnya termasuk lelaki yang menjadi pewaris tahta kerajaan Balok yaitu pangeran Ki Agus Mending atau biasa disebut dengan julukan K.A Mending. Besarnya keinginan pangeran K.A Mending untuk memiliki Yin Galema yang membuatnya mendapatkan tubuh Yin Galema. Hal ini memunculkan terjadinya suatu pengkhianatan yang diketahui oleh makhluk bunian, sehingga menjadikan hubungan percintaan Yin Galema menjadi suram dan menakutkan akibat dari sebuah kutukan bunian.

Karya tari ini digarap dengan tipe tari dramatik dan tipe tari studi, dengan adanya alur yang dibuat saling berhubungan atau saling terkait. Penata mengembangkan studi gerak pada tari 
campak (salah satu kesenian tradisional masyarakat kerajaan Balok) dengan mengambil motif becampak (gerakan mengayun kedua kaki dan tangan secara bergantian). Karya ini memunculkan sosok laki-laki yang menjadi Bunian, dalam hal ini penata menyimbolkan sesuatu yang berbeda alam dengan memunculkan sosok bunian di bagian belakang panggung seperti hanya bayangan saja dan penari perempuan maupun laki-laki lainnya melakukan gerak dengan mengexplor ke tiga karakter tersebut.

Kata kunci : Tiongkok, Yin Galema, Belitung.

\section{ABSTRACT}

A dance piece entitled Cinte Yin Galema taken from the name of a character who is very influential in the Balok kingdom Belitung island and is a daughter of Chinese descent flawless and spirited knight. Yin Galema figure tells Chinese princess who is familiar with the Malay culture such as how to dress and behave manners in Belitung Malay kingdom. This daughter pick a desire and a tremendous desire to keep the sacred promise marriage to a husband who is not from the human race, the husband owned by Yin Galema a creature Bunian which means being descendants of the jinn who have power in Dublin. This work led to the male figure Bunian, in this case the artist symbolizes something different nature to bring Bunian figure on the back of the stage as only a shadow figure of a man that is not visible.

Love life Yin Galema very beautiful, although different in nature but can be mutually touched by the help of the first king of the Balok kingdom with supernatural powers he used in the form of a bracelet powerful and can make Yin Galema entry into the world of creatures Bunian, love life Yin Galema built very perfect, with no single person knows except the first king of the Balok kingdom. Yin Galema known for his beautiful face made all men in the Balok kingdom fall in love and infatuated with the beautiful face, including the man who became heir to the throne Prince Beams ie Ki Agus Mending or commonly known by the nickname K.A Mending. K.A Mending prince big desire to have earned him Galema Yin Yin Galema body. This led to the occurrence of a betrayal is known by the creature Bunian, making relationships Yin Galema be bleak and frightening as a result of a curse Bunian.

This dance work is a type of dance and dramatic dance type of study, with the grooves made interrelated or interdependent. Stylists use a type of study in dance measles (one of the traditional arts of Balok royal ) by taking becampak motif (rocking movement of hands and feet 
ISSN: 1858-3989

alternately). This work led to the figure of the man who became Bunian, in this case the artist symbolizes something different nature to bring Bunian figure on the back of the stage as only a shadow and a female dancer as well as other men do the motion with mengexplor to three characters.

Keywords: China, Yin Galema, Belitung.

\section{PENDAHULUAN}

Pada abad ke-17 pertama kali orangorang Tiongkok mendarat di negeri yang dinamainya Kaulan (nama lain pulau Belitung) dengan kepemimpinan Kaisar Mancu yang pada saat itu membawa putrinya Yin Galema yang masih berusia di bawah 5 tahun $^{1}$. Setelah menitipkan putrinya Yin Galema di kerajaan Balok, Kaisar Mancu tidak pernah kembali dari pelayarannya di daratan Tumasik.

Putri Cina keturunan raja Tiongkok yang masa kecilnya sudah dibesarkan di pulau Belitung dan sudah banyak mengenal kehidupan adat istiadat orang Melayu, bahkan sudah memiliki suami di pulau Belitung, hanya saja suami yang dimilikinya bukan berasal dari bangsa manusia melainkan lelaki dari bangsa jin yang dikenal dengan makhluk bunian. Makhluk bunian ini sebangsa dengan jin, hanya saja makhluk bunian dilahirkan dari perkawinan antara manusia dan jin.

\footnotetext{
${ }^{1}$ Ian Sancin.2009.Yin GaLema Kisah Cinta dan Penggambaran Putri Tiongkok di Daratan Belitong pada abad ke-17. Jakarta:PT Mizan Publika.p.39
}

Kisah cinta yang dimiliki Yin Galema berbeda dengan kisah cinta pada umumnya, menjalin kehidupan pernikahannya dengan makhluk bunian dilakukannya dengan bantuan raja Balok pertama atau sering dikenal sebagai kepala dari para dukun (Ki Ronggo Udo) untuk bisa hidup selayaknya pasangan manusia $^{2}$. Kehidupan yang dijalani Yin Galema dan suaminya tidak diketahui oleh siapapun termasuk penduduk yang berada di kerajaan Balok, karena hal itu Yin Galema masih diperebutkan oleh setiap laki-laki yang melihatnya terutama oleh pewaris tahta kerajaan Balok atau Pangeran yang akan menjadi Raja di masa depan. K.A Mending adalah pangeran kerajaan Balok yang mempunyai wibawa dan ketampanan yang sangat memikat bagi siapapun yang melihatnya. K.A Mending hanya melihat satu perempuan yang memikat hatinya yaitu Yin Galema, karena cintanya kepada Yin Galema yang begitu besar membuat pangeran Balok

\footnotetext{
${ }^{2}$ Ian Sancin.2009. Yin Galema Kisah Cinta dan Penggambaran Putri Tiongkok di Daratan Belitong pada abad ke-17. Jakarta:PT Mizan Publika.p. 503
} 
berhasrat untuk bisa memiliki Yin Galema seutuhya, tanpa dia ketahui bahwa Yin Galema sudah memiliki suami dari bangsa jin. Perdebatan yang panjang antara Yin Galema dan K.A Mending akhirnya membuat Yin Galema kalah dan menyetujui cinta dari K.A Mending dengan memberikan tubuhnya untuk dimiliki dan digagahi oleh pangeran kerajaan Balok.

Pengkhianatan yang terjadi membuat makhluk bunian murka dan mengeluarkan kutukan terhadap istrinya sendiri yaitu Yin Galema. Kutukan tersebut mengatakan :

"Jika aku bukan seorang pemaaf abadilah kutukan yang bersemayam dalam darahmu. Ia meresap dan menyebar perlahan di balik kulitmu yang indah, meski kau bertambah cantik, setiap lelaki takkan berhasrat menyentuhmu karena kulit dan tubuhmu terkutuk sepanjang hidupmu! Hanya lelaki inilah yang ditakdirkan menyentuhmu. Aku akan kau buru sepanjang hidupmu. Jika sampai waktunya darahmu dan darahku menyatu barulah kita mati seutuhnya."3

Kutukan inilah yang menjadikan penderitaan dan penyesalan dalam hidup Yin Galema untuk selamanya dan Yin Galema akan hidup selayaknya makhluk Bunian yang bukan lagi menjadi manusia.

Ketertarikan terhadap kisah cinta Yin Galema yang membuat penata memunculkan esensi gerak dari cinta segitiga dan mulai

${ }^{3}$ Ian Sancin.2009. Yin Galema Kisah Cinta dan Pengembaraan Putri Tiongkok di Daratan Belitong pada Abad ke-17. Jakarta:PT Mizan Publika.p.01 mengeksplorasi gerak tentang keresahan Yin Galema dalam percintaan dan penghianatan serta penyesalan yang dialami Yin Galema. Menunjukkan esensi gerak dalam simbol simbol persetubuhan, penolakan atau terjadinya penghianatan dalam kisah cinta Yin Galema.

\section{PEMBAHASAN \\ A. Proses Penciptaan \\ 1. Rangsang Awal}

Rangsang tari adalah proses untuk mengenal lebih dekat serta mendorong pengetahuan yang lebih dalam tentang karya yang diangkat. Rangsang tari yang digunakan dalam karya tari Cinte Yin Galema adalah rangsang gagasan. Rangsang gagasan dilakukan dengan langkah awal memberikan cerita tentang kehidupan Yin Galema dan latar belakang kisah percintaannya. Penata menggunakan rangsang gagasan dikarenakan penata sendiri menemukan hal yang menarik dalam suatu gagasan percintaan dengan adanya cinta segitiga yang dituliskan dalam novel Yin Galema.

\section{Tema}

Karya tari Cinte Yin Galema mengusung tentang kehidupan cinta segitiga dan pengkhianatan Yin Galema. Yin Galema yang menduakan suaminya yaitu makhluk bunian dengan pangeran kerajaan Balok, sehingga menyebabkan kutukan yang abadi bersemayam di tubuh Yin Galema. Tema tari 
ini membuat penata untuk mempertajam pokok garapan yang dibuat dalam karya agar tetap mengacu pada tema yang telah diususng, dan tema yang dibuat sudah mewakilkan secara garis besar cerita dalam karya tari Cinte Yin Galema.

\section{Judul}

Sebuah judul dalam karya sangat berpengaruh penting sebagai penyampai maksud dalam karya yang digarap, penata menginginkan judul yang diusung bisa memberikan pengertian secara garis besar atau menyampaikan sebuah pesan dalam bentuk tersirat kepada pembaca bahkan penonton. Penata mempertimbangkan maksud yang akan disampaikan maka judul karya tari yang digunakan adalah Cinte Yin Galema. Cinte berarti cinta dalam kata Melayu, dan Yin Galema adalah nama tokoh yang diusung dalam karya ini.

\section{Tipe Tari}

Karya tari Cinte Yin Galema menggunakan bentuk ungkap tari kelompok dan tari duet berpasangan pada gerak yang menyimbolkan tentang perpaduan cinta sepasang kekasih, karya ini digarap dengan tipe tari dramatik, dan tipe tari studi. Karya tari ini menggunakan tipe tari dramatik sebagai landasan awal untuk eksplorasi menciptakan alur yang saling berkaitan dalam bentuk gerak, dan untuk bereksplorasi lebih jauh akan menggunakan tipe tari studi dengan menggambarkan perwujudan dalam bentuk gerak yang mewakili sosok Yin Galema dengan menggunakan pengembangan gerak becampak dan gerak joged melayu. Menggunakan pengembangan gerak silat melayu untuk memperkuat karakter K.A Mending yang berwibawa, dan pengembangan gerak lenggang untuk penari yang berwatak makhluk bunian.

Tipe tari dramatik dan tipe tari studi digunakan untuk menyampaikan pesan dengan makna sebuah gerak dalam karya tari Cinte Yin Galema.

\section{Mode Penyajian}

Mode penyajian yang digunakan dalam karya tari Cinte Yin Galema adalah simbolik representasional.

\section{Gerak Tari}

Gerak yang dimunculkan dalam karya Cinte Yin Galema adalah pengembangan gerak dasar becampak, ngigal, dan 11 kembang silat Belitung. Karya ini memunculkan gerak yang banyak menggunakan ungkapan ekspresi sebagai pengungkapan rasa dalam konflik yang dimunculkan tokoh.

\section{Adegan Tari}

Adegan dalam karya tari Cinte Yin Galema memiliki 5 rincian adegan yaitu adegan introduksi yang ditarikan 3 orang penari kemudian menjadi 11 orang penari sebagai bentuk kisah cinta segitiga. Adegan 1 
dan adegan 2 menceritakan tentang watak tokoh Yin Galema dan K.A Mending dengan studi gerak dasar becampak, ngigal, dan 11 kembang silat. Adegan 3 sebagai bentuk pertemuan dan penolakan Yin Galema atas cinta K.A Mending, sedangkan adegan 4 adalah penyerahan cinta Yin Galema kepada K.A Mending sehingga menimbulkan penghianatan dan menjadi penyebab keluarnya sebuah kutukan untuk Yin Galema.

\section{Penari}

Karya tari yang berjudul Cinte Yin Galema melibatkan11 penari. Pemilihan 11 penari berdasarkan penelitian penata dengan menemukan 11 macam kembang silat dari ke11 dukun kampung yang berkuasa di Belitung. 11 dukun kampung mempunyai hubungan erat dengan dunia bunian karena dalam adat istiadat Belitung untuk memasuki dunia bunian memerlukan izin dari 11 dukun yang ada di Belitung. Jumlah 11 penari dibuat penata dengan rincian lima orang penari perempuan yang menjadi visual gerak tokoh Yin Galema, enam orang penari laki-laki sebagai tokoh dari makhluk bunian dan K.A Mending. Penari perempuan yang menjadi tokoh Yin Galema memiliki tubuh yang hampir sama dengan penata dikarenakan lima penari perempuan ini termasuk penata bergerak menceritakan satu tokoh, dan untuk mempermudah penata dalam mentransfer gerak dengan membentuk ketubuhan penari.
Enam penari laki-laki yang dipilih penata yaitu memiliki tubuh yang tinggi dan berkepribadian lembut untuk mempermudah penata memasukkan karakter makhluk bunian, dan memiliki tubuh yang kuat sehingga terlihat berwibawa selayaknya karakter dari K.A Mending.

\section{Tata Rias dan Busana}

Berkaitan dengan tema karya tari ini penata menggunakan rias pada penari perempuan adalah rias putri Cina dengan karakter dari alis yang sedikit naik dan karakter dari mata yang dibuat tajam, dan rias rambut yang diikat bagian bawah seperti sanggul kecil di bagian belakang leher dengan belahan rambut di bagian tengah yang biasa digunakan oleh putri Cina. Hiasan kepala penari perempuan menggunakan ikat teratai merah di bagian depan kepala. Busana yang digunakan penari perempuan yaitu bernuansa Cina Melayu dengan baju kuning emas bernuasa Cina dan celana panjang Melayu berbahan dasar lembut berwarna merah dan dilapisi kain songket merah di bagian depan celana. Kostum untuk laki-laki menggunakan pakaian kerajaan Belitung berwarna merah dengan kain songket kuning dan celana merah, memakai hiasan kepala seperti setanjak kurong. Warna kuning yang dipilih merupakan warna keberuntungan bagi masyarakat Tiongkok dan dipadukan dengan warna merah yang mencolok. Warna merah adalah salah 
satu warna khas dari kerajaan Balok dengan melambangkan keberanian dari masyarakat Melayu.

\section{Musik Tari}

Musik dalam karya tari merupakan elemen terpenting sebagai pendukung karya, selain berperan sebagai pembangun suasana musik juga berperan dalam memegang tempo penari. Karya ini menggunakan live music sebagai pengiring garapan tari. Musik yang bernuansa Melayu dan Cina dibuat semenarik mungkin dengan penambahan beberapa instrumen sebagai pemanis. Penata menggunakan musik secara live untuk memperkuat suasana dalam karya ini dan akan mempermudah penata menetapkan hitungan untuk bisa lebih fokus terhadap patokan hitungan yang sudah dibuat penata, hal ini juga bisa untuk meminimalisir gerak improvisasi. Beberapa alat musik yang digunakan adalah gambus, aqordion, rebana,babano, klinangan, huluse', biola, beduk, bass, vokal.

\section{Tata Rupa Pentas}

Bentuk garapan yang dibuat penata sangat menyesuaikan dengan ruang tari yang sudah disediakan misalnya ruang tari seperti procenium stage, panggung terbuka, dan arena. Dalam karya Cinte Yin Galema memilih ruang tari dalam bentuk procenium stage.

\section{Tata Cahaya}

Pencahayaan menjadi unsur pendukung penting di dalam pementasan sebagai penguat suasana dan membuat bentuk sebuah bayangan. Penata menggunakan warna-warna terang seperti merah sebagai suasana pendukung menegangkan. Tambahan cahaya pada bagian belakang setting kain putih untuk memunculkan shadow penari.

\section{B. Realisasi Karya}

Riset dan wawancara secara langsung kepada narasumber merupakan tahap untuk mendapatkan informasi yang sangat dibutuhkan dalam penciptaan karya tari ini.

\section{Realisasi Musik Tari}

Menggunakan beberapa instrumen yaitu Bonang selendro dengan nada 1,2,3,4,5 dan 6 , aqordion, bass electric, huluse', babano, gambus, rebana, multi perkusi, biola, gong, kempul, tamborin dan vokal. Vokal yang digunakan berasal dari syair yang terdapat di dalam novel Yin Galema. Pada bagian Introduksi terdapat vokal sebanyak 3 bait yaitu

Ladon la ya ladon. Sayang sayang...

Sebuah kate kupendam, laksane mutiare de dalam laut

Jika deselam baju kan basah, ndak deselam atiku resah.

Murong atiku malu berucap, kaluk berucap desalah de tangkap

Bile membisu ati kan ragu, di ati kawan siape nok tahu.

Jika angin betiup renda,sejoknya sampai kelubok ati 
Kalau lah kawan hendak berkawan, carilah biak kawan sejati. ${ }^{4}$

Vokal yang digunakan sebagai pembuka dibagian introduksi sebelum masuk pada bagian syair adalah Ladon la ya Ladon. Sayang sayang. Kalimat ini berarti sebuah pernyataan untuk menyampaikan suatu cerita yang di syairkan dengan bahasa Belitung. Penata musik pada bagian ending juga menggunkan vokal dari bahasa tradisi yang artinya mengutuk dan mencaci maki karena suatu pengkianatan yaitu Awar, Sejuer, Jaber yang dikembangkan dalam permainan dinamika vokal.

\section{Realisasi Tata Rias dan Busana}

Foto kostum penari perempuan dan lakilaki.

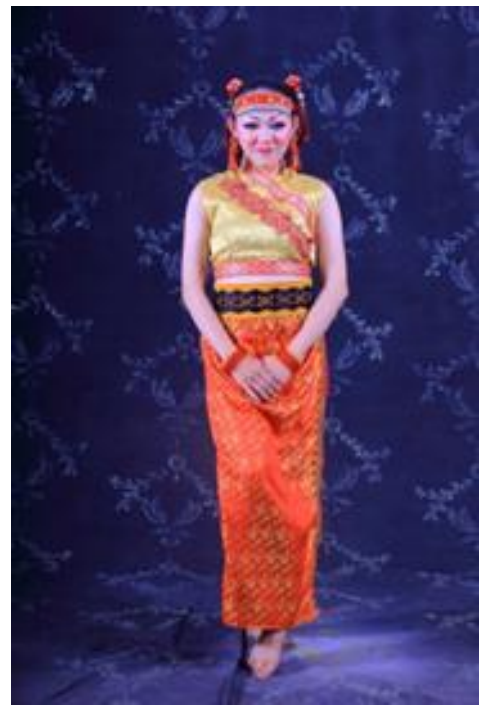

Gambar 1 : Foto kostum penari perempuan tampak depan (Foto: Ody 12 Januari 2017 di Studio 2 Jurusan Tari ISI Yogyakarta).

${ }^{4}$ Ian Sancin, Yin Galema Kisah Cinta dan Pengembaraan Putri Tiongkok di Daratan Belitong padaabad ke-17, Jakarta : PT Mizan Publika 2009, hlm 80-84.

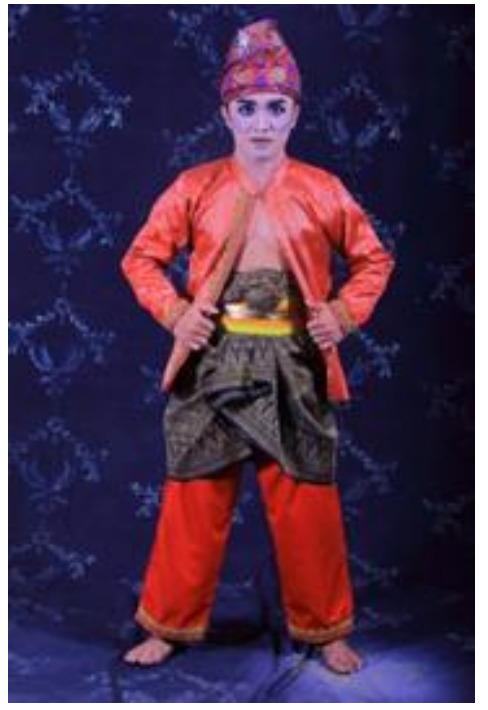

Gambar 2 : Foto kostum penari laki-laki tampak depan (Foto: Ody 12 Januari 2017 di Studio 2 Jurusan Tari ISI Yogyakarta).

\section{Realisasi Elemen Pendukung Lainnya}

Setting panggung di bagian back drop dibuat sebagai perumpamaan dunia lain yang dikombinasikan dengan kain putih dan tata cahaya yang memunculkan bentuk shadow pada penari. Penata memunculkan secara visual tentang dimensi yang berbeda antara manusia dan makhluk bunian agar terdapat pemahaman bagi penonton tentang perbedaan alam yang diciptakan penata.

Penambahan dua payung pengantin di bagian belakang backdrop sebagai penguat sebuah kerajaan dari makhluk bunian, payung pengantin diletakkan dibagian depan bingkai seperti tombak pengawal. Terdapat 3 tingkatan payung dengan warna merah, kuning, dan putih sebagai simbol dari ke3 warna kerajaan Balok di pulau Belitung. Warna merah memiliki arti sebuah keberanian, warna kuning 
mempunyai arti suatu yang sangat berharga atau diibaratkan dengan emas dan warna putih berarti suci dan tulus.

Penggunaan tali pada bagian ending menyimbolkan sebagai sebuah kurungan berarti kutukan yang diterima Yin Galema, yang menjerat sehingga Yin Galema terperangkap di dalamnya.

\section{Evaluasi}

\section{1). Introduksi}

Koreografi ini diawali dengan menampilkan tiga orang penari, yaitu dua penari laki-laki dan satu penari perempuan. Bagian introduksi dikemas untuk memperkenalkan secara singkat isi dari karya atau pengantar untuk adegan-adegan selanjutnya, menampilkan karakter dalam tiga tokoh yang diangkat dan pengantar dalam bentuk konflik yang akan diulas diadeganadeagan selanjutnya dalam karya.

Front certain dibuka mengiringi tiga penari yang bergerak ke bagian tengah panggung dengan dilanjutkan suasana gerak sebagai ingatan kembali terhadap cinta Yin Galema dengan kekasihnya yang begitu indah dan sangat dinikmati oleh sepasang kekasih. Menampilkan sepasang penari yang melakukan gerak sebagai penyimbolan dari persetubuhan dibagian back drop dan delapan penari bergerak menyimbolkan perasaan dari hasrat sepasang kekasih yang jatuh cinta, sedangkan satu orang penari laki-laki bergerak kontras yang melambangkan kebencian atau amarah K.A Mending melihat kisah cinta Yin Galema dan kekasihnya.

Sudut pandang yang dibuat penata adalah sudut pandang dari tokoh Yin Galema, Keresahan yang dialami Yin Galema dan penyebab kutukan abadi yang bersemayam dalam tubuhnya menjadi acuan dalam pembuatan alur karya Cinte Yin Galema.

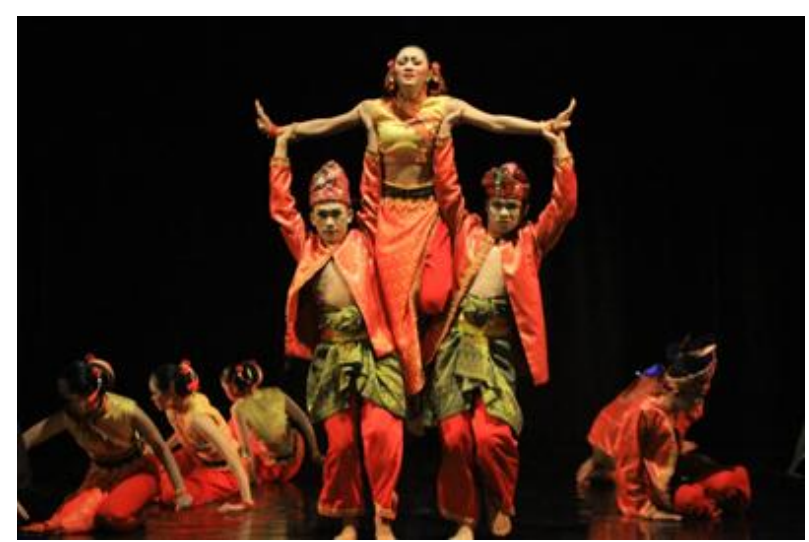

Gambar 3 : Bentuk lifthing pada adegan introduksi (Foto : Ody 12 Januari 2017 di proscenium stage ISI Yogyakarta).

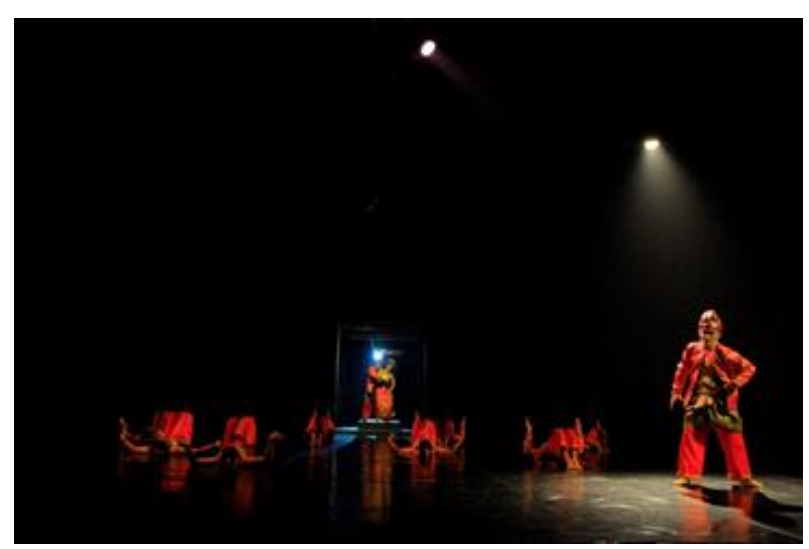

Gambar 4 : Bentuk pola lantai pada adegan introduksi (Foto : Ody 12 Januari 2017 di proscenium stage ISI Yogyakarta). 


\section{2). Adegan 1}

Adegan 1 merupakan bentuk ungkap kebahagiaan Yin Galema dengan pengembangan gerak dasar becampak dalam pengembangan ruang dan waktu. Adegan ini dilakukan oleh empat penari perempuan dengan gerak sebagai tokoh Yin Galema. Suasana yang dimunculkan tidak hanya pengungkapan dari kebahagiaan cinta Yin Galema dengan kekasihnya dalam perbedaan alam yang dimunculkan pada akhir dari bagian satu, dengan menggunakan gerak antu berayun yang menyimbolkan bahwa adegan ini membawa suasana masuk ke dunia Bunian.

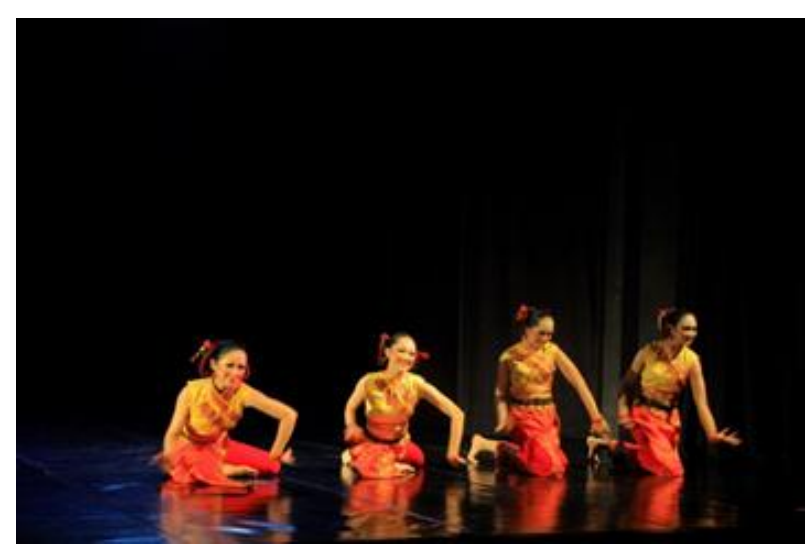

Gambar 5 : Pose dalam motif gerak antu berayun dalam adegan 1 (Foto : Ody 12 Januari 2017 di proscenium stage ISI Yogyakarta).

\section{3). Adegan 2}

Koreografi dalam adegan ini dikemas dalam bentuk gerak pertemuan dari Yin Galema dan K.A Mending menampilkan 8 orang penari dengan memunculkan konflik penolakan dan permusuhan dengan menggunakan focus on three point. Memunculkan esensi gerak keresahan dari Yin
Galema dan penolakan yang diekspresikan kedalam bentuk gerak. Pada bagian ini penata lebih mengulas dan menggunakan gerak silat Melayu untuk sebuah perlawanan. Penata memunculkan studi gerak silat pada adegan ini dengan ke-6 penari laki-laki sebagai penyampaian sifat kewibawaan seorang pangeran untuk menaklukan cintanya. Gerak silat yang dikomposisikan dengan pengembangan ruang, waktu, dan tenaga dilengkapi motif ngigal sebagai penyimbolan bahwa penari laki-laki sudah siap untuk menaklukan keangkuhan dari Yin Galema.

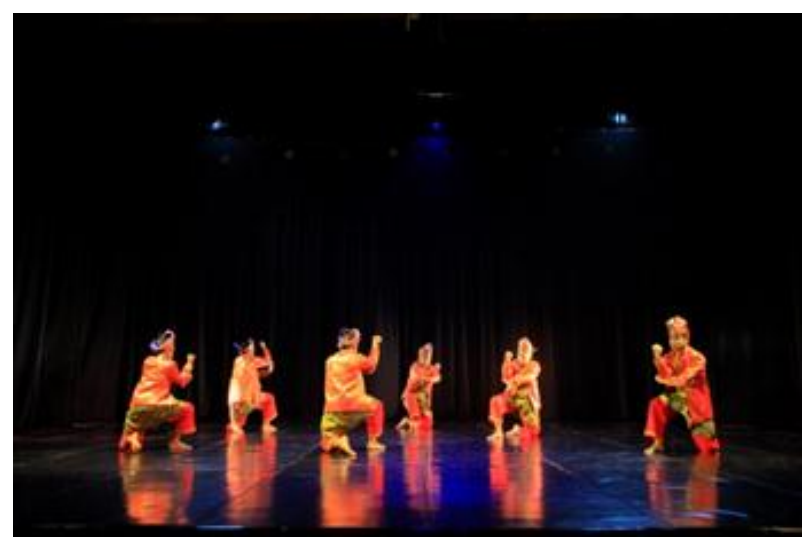

Gambar 6 : Bentuk pola lantai pada adegan 2 (Foto : Ody 12 Januari 2017 di proscenium stage ISI Yogyakarta).

\section{4). Adegan 3}

Kewibawaan seorang pangeran bisa ditaklukkan oleh keangkuhan dan kecantikan Yin Galema yang menjadikan awal peperangan dan pergulatan batin antara Yin Galema dan K.A Mending. Adegan ini menjadi klimaks dari karya tari ini dengan pengemasan dinamika yang mendukung suasana tegang dalam pergulatan dan 
peperangan. Pengembangan 11 motif Kembang silat Melayu Belitung dengan menampilkan 11 penari yang secara bergantian keluar masuk panggung untuk mendukung suasana kericuhan. Akhir dari adegan 3 menjadikan klimaks kekalahan dan penyerahan diri Yin Galema kepada K.A Mending, dengan memasrahkan tubuhnya untuk dimiliki oleh K.A Mending.

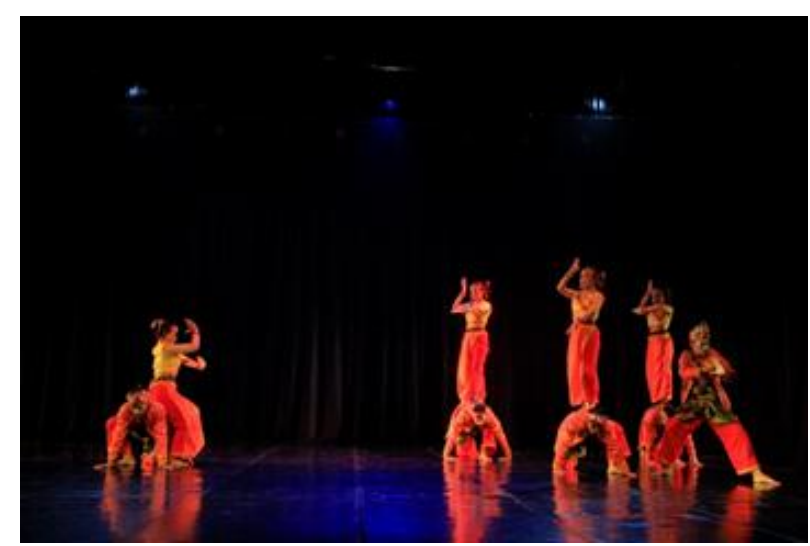

Gambar 7 : Bentuk pola lantai pada adegan 3 (Foto : Ody 12 Januari 2017 di proscenium stage ISI Yogyakarta).

\section{5). Adegan 4 / Ending}

Bagian akhir dalam koreografi ini mejadikan suasana anti klimaks atau penurunan suasana, dengan mewujudkan penyerahan tubuh Yin Galema terhadap K.A Mending. Persetubuhan yang dikemas dalam koreografi duet dikemas semenarik mungkin dan membuat suasana keresahan dalam diri Yin Galema atas pengkhianatannya. Koreografi ini menggunakan shadow pada bagian belakang panggung sebagai bentuk perwujudan dunia yang berbeda. Menampilkan satu orang penari laki-laki yang bergerak dengan mengekplor seting berupa shadow sebagai bentuk kemarahan dan pengucapan sumpah atau kutukan yang disampaikan makhluk Bunian. Adegan ini menyampaikan isi dari kutukan makhuk Bunian kepada Yin Galema atas pengkhianatan cinta yang dilakukan Yin Galema.

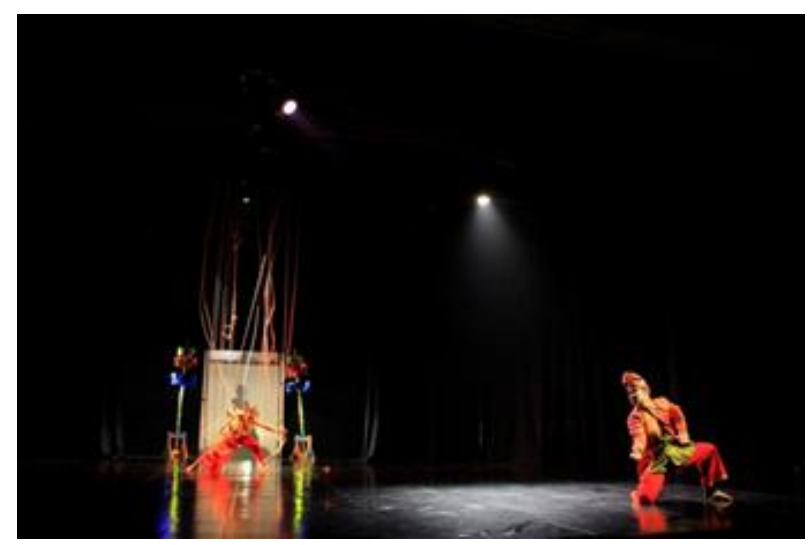

Gambar 8 : Bentuk pola lantai dan seting pada adegan ending (Foto : Ody 12 Januari 2017 di proscenium stage ISI Yogyakarta).

\section{PENUTUP}

Karya tari Cinte Yin Galema adalah bentuk karya tari yang berpijak pada tradisi, yang mengembangkan gerak-gerak dasar Melayu Belitung dan gerak-gerak dasar silat. Banyak pesan yang bisa dimbil dari karya tari ini yaitu : "sebuah pengkhianatan dalam bentuk apapun sangat tidak baik dan akan berakibat buruk dalam kehidupan sekarang dan mendatang". Jika sudah memulai suatu hubungan maka akan menjadi tanggung jawab yang sangat besar untuk menjaganya dan mengambil resiko.

Mengemas karya tari dengan mengembangkan beberapa unsur-unsur gerak 
dari tari Campak dan silat Melayu dengan penambahan pola ruang, waktu, suasana, dan aksi. Penyampaian maksud dan tujuan dari penata tentang nilai-nilai kesetiaan dan akibat dari sebuah pengkhianatan bisa langsung diterima oleh seluruh pendukung maupun penonton.

Memerlukan pengetahuan dan pemahaman yang lebih dalam untuk mengulas suatu objek yang akan diangkat dalam sebuah karya, sehingga akan mempermudah dalam mengaplikasikan ide penciptaan ke realisasi penciptaan. Sebuah karya memiliki nilai estetika tersendiri tergantung dari cara pengemasan dan objek yang akan diangkat, maka dari itu untuk selanjutnya harus lebih paham dan memperhatikan nilai-nilai estetika dalam sebuah pertunjukan.

\section{DAFTAR SUMBER ACUAN}

\section{A. Sumber Tertulis}

Groeneveldt, W.P 2009. Nusantara Dalam Catatan Tionghoa. Komunitas Bambu Jakarta.

Hadi, Y. Sumandiyo. 2003. Aspek-Aspek Dasar Koreografi Kelompok.Elkaphi Yogyakarta.

2006. Seni dalam Ritual Agama.Pustaka Yogyakarta.

2012. Koreografi BentukTeknk isi. Cipta Media Yogyakarta.
La Meri. 1975 Elemen-elemen Dasar Komposisi Tari. Terjemahan Soedarsono. Yogyakarta: Lagaligo.

Martono, Hendro 2008. Sekelumit Ruang Pentas Modern dan Tradisi. Cipta Media Yogyakarta.

2010. Mengenal Tata

Cahaya Seni Pertunjukan. Cipta Media Yogyakarta.

2012.

Ruang

Pertunjukan dan Berkesenian. Cipta Media Yogyakarta.

Reid, Anthony. 2010. Sumatera Tempoe Doeloe. Tim Komunitas Bambu. Jakarta.

Sancin,Ian. 2006. Yin Galema.Serambi Ilmu Semesta. Jakarta.

Sancin, Ian. 2015 ARAI Novel Sejarah Kerajaan Balok Belitong Abad ke-18. PT Serambi Ilmu Semesta. Jakarta.

Sukisman,W.D. 1992. Sejarah Cina Kontemporer. PT Pradnya Paramita. Jakarta.

Taniputera,Ivan. 2013. History Of China. AR-RUZZ Media.Yogyakarta.

Yah, Salim. 1999. Cerite Adat Belitong. PT.TIMAH. Belitung.

Bahasa

Reality, Tim. 2008. Kamus Terbaru PUBLISHER.Surabaya.

\section{B. Filmografi / Diskograi}

a. Teater kolosal "Yin Galema" disutradarai oleh iqbal H.Saputra.

b. Tari Yin Galema karya Renny Destiani dalam ujian mata kuliah koreografi 3. 
ISSN: 1858-3989

c. Tari "becampak" karya sanggar Wilsen kepulauan Bangka Belitung.

\section{Narasumber}

a. Ian Sancin, penulis novel Yin Galema bertempat tinggal di jalan Ahmad Yani No 12 Kelurahan Pangkalalang.

b. Iqbal H.Saputra, Sutradara teater kolosa Yin Galema bertempat tinggal di jalan Aik Ketekok No 23 Kelurahan Paal Satu. 
